\title{
A Declaração Universal sobre o Genoma e Direitos Humanos: um Novo Modelo Jurídico para a Natureza?*
}

\author{
Gosé OAntonio Penes Gediel
}

Doutor em Direito das Relações Sociais e Professor Adjunto da UFPR.

A

s ciências biológicas, baseadas em

um modelo experimental, atingiram um novo patamar no final do século $\mathrm{XX}$, ao mapearem, para organizar seqüencialmente, os pares de cromossomos de toda a humanidade. O mapeamento proposto descreve o genoma humano, o qual vem definido no art. $1^{\circ}$, da Declaração Universal sobre Genoma e Direitos Humanos, coño "unidade fundamenta! de todos os membros da família humana". ${ }^{1}$

O uso, acesso e valor de mercado desse conjunto de informações genéticas humanas mapeadas têm tornado cada vez mais tenso o feixe de relações estabelecidas nas sociedades e entre sociedades. Não é por outra razão que o próprio título da $\mathrm{De}$ claração aponta para uma dimensão que se sobrepōe à particularidade das ordens jurídicas nacionais e se dirige ao âmbito de uma comunidade ideal-universal.

A presença dessa dimensão universal e a referência aos direitos humanos valorizam. a "lógica de comunidade", calcada na unidade da espécie humana, mids, apesar úéssis pius. pósitos, a Declaração é um documento jurídico que pretende regular comportamentos individuais, coletivos, estatais e comunitários, situando-se, por isso, no "pilar da regulação" ou da normatividade clássica. ${ }^{2}$

- Trabaho apresentado no $1^{2}$ Seminário da Segunda Fase do Projeto Virada de Copérnico, da Pós-Graduaçăo em Direito da UFPR.

1. Declaraçăo Universal scbre Genoma e Direitos Humanos, aprovada na $29^{\circledR}$ Conferência Geral da UNESCO, em 11 de novembro de 1997.

2. "De acordo com a leitura desenvolvida por Boaventura de Sousa Santos, o projeto sócio-cultural da modernidade, constituido entre os séculos XVI e o final do século XVIII, é um projeto completo e ambicioso assente em dois pilares: o pilar da regulaçăo $\mathrm{e}$ opilar da emancipaçăo. Cada um deles é, no entanto, uma construçăo multicimensional. Assim, ao pilar da regulação reconduzemse a lógica do mercado, a lógica do Estadoe a logica da comunidade, enquanto no pilar da emancipaçăo confluem a racionalidade estético-expressiva, a racionalidade moral-prática e a racionalidade cognitivo-instrumental." (PUREZA, José Manuel. "Globalizaçäo 
Os conflitos de interesses que a Declaração pretende regular se exteriorizam em várias esferas das sociedades contemporâneas e se acentuam em virtude de um modelo que permite a apropriação privada de ganhos econômicos obtidos pela circulação onerosa de produtos biotecnológicos, no mercado, contrastando com a forma gratuita com que os elementos orgânicos comuns a toda a humanidade são cedidos pelos sujeitos pesquisados. ${ }^{3}$

No âmbito do Direito Internacional, do Direito Comunitário e das ordens jurídicas nacionais, grande parte das soluções para esses conflitos são buscadas no Direito Privado clássico e se dirigem à esfera interindividual. O procedimento regulatório inaugurado pelo Direito Civil - que prioriza a prévia definição da natureza jurídica do bem, das formas de sua transmissão e da clara definição de sua titularidade -, se torna absolutamente aplicável ao genoma e às informações genéticas dele extraída, visto que, na sociedade de mercado, a simples possibilidade de circulação de um bem lhe agrega valor econômico e acirra a disputa entre os titulares originários e derivados desse bem.

\section{O recurso a essa técnica regulatória} privatista se aplica ao genoma humano também porque, no âmbito da Declaração, a sua titularidade difusa, comum a toda a humanidade, só é juridicamente afirmada em sentido "simbólico" (art. $1^{\circ}$ ), pois, nos termos do art. $5^{\circ}$ da Declaração, cada sujeito é colocado na condição de titular de direito sobre o genoma, sendo-lhe exigido, inclusive, o consentimento individual informado para permitir o acesso a esse bem.

Tomando por base esse quadro de referências teóricas privatistas, a Declaração propõe soluções jurídicas que visam tutelar interesses particulares e comunitários, admitindo a transferência de titularidade, gratuita ou onerosa, do genoma e de informações genéticas humanas: a) durante o acesso dos dados, in situ, pelos pesquisadores; b) quando ocorre a transformação dos resultados colhidos, pela pesquisa, em produtos destinados a circularem no mercado; c) por ocasião do acesso, para uso terapêutico ou industrial, de produtos biotecnológicos já em circulação no mercado. ${ }^{4}$

$\mathrm{Na}$ fase em que se dá o acesso aos elementos naturais que servirão de base para

e direito internacional: da boa vizinhança ao patrimônio comum da humanidade". In Lua Nova - Revista de Cultura e Politica. Sáo Paulo, n² 30 (Direito e Direitos), 1993, p. 87)

3. "Déchiffré et éclaté - en un mot, décodé -, le code génétique a été l'objet d'une opération d'axiomatisation qui vise à le reternitorialiser et à linscrire dans le régime de la propriété privée. Pour $\infty$ faire, il va falloir transformer l'information en tant que différence qualitative en différence quantitative et abstraite, bref, 'conférer un prix à la valeur', pour reprendre les mots d'une paysanne colomoienne quand elle apprit ce quel'on prétendait faire, désormais, de la vievégétale, animale et humaine." (SANTOS, Laymert Garcia dos. Code primitit/code génétique la consistance d'un voisinage. In ALLIEZ, Eric (Dir.) Gilles Deleuze: une vie philosophique. Paris: PUF, 1996, p. 425.

4. O exame dos termos acesso e uso, articulados com os momentos do processo científico e de produçắo em que o Direito é chamado para solucionar conflitos de interesses, nos fornecem uma exposiçăo sumária do conjunto de problemas e soluçōes atuais, sempre que se tratar de dados, informaçoes e produtos biotecnológicos de origem humana. Saliente-se que o ordenamento juridico brasileiro que trata do acesso, uso e controle de recursos genéticos (Lei $n^{\imath} 8.974 / 95$, Resoluçáo n² 196/96, do Conselho Nacional de Saúde e Instruçăo Normativa $n^{2} 897$, da CTNBio) vedam toda e qualquer aplicaçăo visando a alteraçăo de caracteristicas genéticas humanas, silenciando sobre a biotecnologia aplicada aos seres humanos. 
a pesquisa de mapeamento do genoma humano, pode se estabelecer um visível conflito de interesses entre o sujeito pesquisado e pesquisadores envolvidos na pesquisa, principalmente, porque as definições clássicas de direito subjetivo se apresentam inadequadas para identificar, com clareza, os poderes e deveres do indivíduo sobre sua dimensão corporal..$^{5}$

Orientado pela noção de direito subjetivo, o Direito contemporâneo procura adaptar a vontade negocial do sujeito utilizando-se da forma de consentimento informado, para permitir o acesso voluntário ao corpo humano. ${ }^{6}$

O consentimento - elemento volitivo essencial à criação, modificação ou extinção dos vínculos jurídicos dos sujeitos a respeito de coisas - passa a figurar nos textos jurídicos acompanhado de atributos específicos (liberdade, esclarecimento e informação), sempre que se cuide de operacionalizar a vontade nas relaçc̃es jurídicas a respeito do corpo humano.

Com essa modificação, o Direito P̂rivado procurou amenizar o valor da força vinculante da vontade abstrata do sujeito ao the acrescentar elementos da realidade concreta de cada indivíduo, em cada situação existencial. A mera qualificação da vontade expressa (consentimento) se mostra, contudo, insuficiente para tutelar os interesses do sujeito pesquisado, ao permitir o acesso ao genoma, pelos pesquisadores.

A perspectiva privatista atual continua, portanto, a pressupor que o emitente do consentimento informado; no gozo da sua autonomia privada, tem pleno conhecimento e clara avaliação dos riscos e potencialidades da pesquisa. A expressão individual da vontade, sob essa ótica, se dirige, primordialmente, a tutelar os direitos da personalidade do emitente do consentimento. Os efeitos dessa declaração, contudo, podem atingir a esfera de outros sujeitos, uma vez que o genoma, nos termos da própria Declaração (art. 19), "subjaz à unidade fundamental de todos os membros da família humana e também ao reconhecimento de sua dignidade e diversidade inerentes". Seu acesso, ainda que consentido por um só indivíduo, pode pôr ern risco a biodiversidade e a sobrevivência de outras espécies.?

No plano puramente individual, o consentimento informado traz, ainda, como

5. Segundo Laymert, "para el Derecho clasificar es trazar límites; pero sobre todo trazar límites que regulen los impulsos del sujeto, que le impidan hacerse todopoderoso, que moderen su voluntad. Por eso mismo, Edelman considera que el Derecho está en permanente conflicto con el derecho subjetivo, al final I a realización del narcisismo absoluto implicito en el derecho subjetivo significaría el fin del própio Derecho". (SANTOS, Laymert García dos. Tecnociencia y pérdida de lo humano: de la crisis del stjeto de derecho a la necesidad de derechos coletivos. In FLÓREZ, Margarita (Org.). Diversidad biologica y cultural. Bogotá: llsa, 1998. p. 27.

6. A Declaraçăo Universal sobre Genoma Humano e Direitos do Homem, em seu art. $5^{\circ}$, acolhe o consentimento informado individual como um dos requisitos para 0 acesso dos pesquisadores ao genoma de qualquer pessoa. Essa catogoria vem sendo elaborada pelo Direito para permitir todo tipo de intervençöes corporais e exige que o consentimento, além de livre, sem coaçöes, seja esclarecido, a respeito dos riscos, vantagens e desvantagens da intervençăo.

7. “Ainsi, la Déclaration se préoccupe également du génome humain dans son sens universel, le génome qui conceme les familles les communautés ef l'Humanité, d'où le besoin d'examiner la possibiité du partage de l'ADN et d'utilisation de linformation 
principal efeito jurídico localizar no seu emitente toda a responsabilidade pelos ris$\cos$ da atividade científica experimental, excluindo a responsabilidade individual $\mathrm{e}$ social do cientista e dos organismos de pesquisa.

Nesses termos, a valoração jurídica da vontade abstrata de um dos sujeitos do pólo da relação jurídica, aliada ao modelo de ciência experimental, abre possibilidades de conseqüências danosas imprevisíveis, para o próprio emitente do consentimento, para o seu e para outros grupos sociais.

$\mathrm{O}$ acesso aos dados genéticos exige, por tudo isso, novos modelos jurídicos aptos a reconhecer e tutelar titularidades difusas e coletivas de direitos, decorrentes da identidade biológica presente entre pessoas e grupos de pessoas. É possível afirmar que a biotecnologia acabou por gestar, ao lado do status nacional, civil e familiar, um status biológico, que exprime, juridicamente, a desterritorialização provocada pela recente revolução biotecnológica. ${ }^{8}$

Para compreender tal identidade, é preciso levar em consideração o fato que, apesar de se localizarem em um determinado sujeito singular (indivíduo), cidadão de um Estado soberano e membro de uma fa- mília, os dados genéticos fazem parte de um conjurito, no qual se interligam e são complementados por dados provenientes de outros indivíduos. Por isso, os efeitos do acesso consentido a determinado organismo humano não se esgota no âmbito da relação intersubjetiva (interindividual), com a finalidade de operar a transmissāo de direitos sobre eles, regulada nos moldes de uma ordem jurídica particular.

Pela via da identidade biológica entre sujeitos pesquisados ou entre destinatários de produtos biotecnológicos, constrói-se comunidades de interesses e direitos, patrimoniais ou extrapatrimoniais, presentes e futuros, entre sujeitos sem qualquer vinculação política ou jurídica, que se refletem na esfera social e interferem na subjetividade jurídica. ${ }^{9}$

A gratuidade ou onerosidade da transferência de titularidade dos produtos obtidos com base em material e informações genéticas humanas, cientificamente trabalhadas, engendra uma outra gama de pıoblenas igualmente difíceis de sulucionar, com a aplicação da lógica do Direito Privado clássico.

Sob esse aspecto, é importante frisar que os bens objeto dessas novas relações

génétique humaine en commençant encore une fois avec des modèles provenant du domaine de la biodiversité." (KNOPPERS, Bartha Maria. Le génome humain: patrimoine commun de l'Humanité? Québec: Museu de la civilisation, 1999. p. 19).

8. SANTOS, Laymert García dos. Code primitif/code génétique la consistance d'un voisinage. In ALLIEZ, Eric (Dir.) Gilles Deleuze: une vie philosophique. Paris: PUF, 1996. p. 424.

9. A ampliaçăo da identidade biológica, para além dos laços de consagüinidade, revelada pela Biotecnologia, é claramente perceptivel, mas a doutrina tem advertido para os perigos de uma concepção puramente sócio-biológica do humano (LECLERC, Bruno; MÉLANÇON, Marcel J.; GAGNÉ, Richard; NOOTENS, Suzanne. Espoirs, risques et responsabilités. In MÉLANÇON, Marcel J.: LAMBERT., Raymond D. (Dir.) Le génome humain: une responsabilité scientifique et sociale. Quebec: Les Presses de L'Université Laval, 1992. p. 125), e, ainda, para a valorização da normalidade genética em desfavor da especificidade. (RODOTÀ, Stefano. Tecnologie e diritti. Bologna: II Mulino, 1995. p. 130-131). Com essa mesma preocupaçăo, foram estabelecidos o teor dos arts. $1^{2}$, $2^{2}$ e $3^{0}$ da Dedaraçăo Universal sobre Genoma Humano e Direitos do Homem. 
jurídicas podem ser: dados genéticos in natura; informaçōes genéticas resultantes da organização científico-operacional desses dados; e, ainda, produtos desenvolvidos a partir dessas informações. No decurso desse processo biotecnológico, o espectro de relações que o direito busca regular abrange, em primeiro plano, as estabelecidas entre o sujeito pesquisado, fornecedor do material gratuito da pesquisa, e o pesquisador; em segundo plano, entre o titular do trabalho científico e o titular do produto; em terceiro plano, entre o titular do produto e os usuários ou consumidares.

Na solução desses conflitos, o Direito tem adotado duas lógicas jurídicas, aparentemente antagônicas. Uma que se pauta pela gratuidade da transferência de titularidade de elementos corporais humanos, regulando o comportamento do sujeito, com vistas ao acesso a seu corpo para pesquisa. Outra que admite a circulação onerosa de produtos genéticos.

Nessa linha de entendimento, a Cursitituição biasilcira, por cücmplc, esta beleceu em seu art. $199, \S 4^{\circ}$, o princípio da gratuidade, que impede a cessão ou transmissão onerosa de elementos do corpo humano, antecipando-se ao conteúdo da Declaração Universal sobre o Genoma Humano e os Direitos do Homem, que, em seu art. $4^{\circ}$ dispõe: "O genoma humano em seu estado natural não deve dar lugar a ganhos financeiros."10
Com base nessa principiologia jurídica, afirma-se a indissociabilidade do corpo e sua inalienabilidade.

A gratuidade do acesso aos dados genéticos conjugada com a exigência de consentimento livre e esclarecido se apresentaria, em princípio, suficiente para estabelecer a distinção entre o regime jurídico destinado a regular relações jurídicas, com finalidade científica, e o regime específico à transferência de titularidade de coisas por sujeitos de direito. A peculiaridade desse regime prevê, ainda, a tutela da personalidade do sujeito pesquisado, assegurando-lhe o sigilo das informações.

Como conseqüência, afasta toda e qualquer possibilidade de o sujeito pesquisado, que permitiu gratuitamente $o$ acesso aos dados genéticos, participar dos ganhos econômicos obtidos com sua trans. formação em produtos biotecnológicos. A justificativa para esse tratamento jurídico encontra na indisponibilidade dos direitos da personalidade seu principal argumento. Além disse, os direitos do sujeito pesniricado recaem sobre o genoma em seu "estado natural" e sobre esses direitos pesa a vedação do art. $4^{\circ}$ da Declaração, que estabelece: "O genoma humano, em seu estado natural, não deve dar lugar a ganhos financeiros." Essa solene declaração do princípio da gratuidade, entretanto, só se aplica ao sujeito pesquisado e não retira o genoma humano do jogo do mercado que se expressa,

10. Declaração Universal sobre Genoma e Direitos Humanos, aprovada na $29^{a}$ Conferēncia Geral da UNESCO, em 11 de novembro de 1997. 
no plano jurídico, por meio da transferência onerosa da titularidade de produtos biotecnológicos.

O instrumental jurídico elaborado sob a ótica do mercado tem, ainda, a finalidade de dirimir conflitos entre o profissional que realizou o mapeamento dos dados genéticos (pesquisador) e aquele que disponibiliza e organiza todos os meios de produção (empreendedor), para atribuir a este último sujeito a titularidade jurídica sobre produtos derivados da atividade científica e industrial.

Para regular esse conflito de titularidades, o Direito vem se utilizando de categorias próprias do direito patrimonial sobre coisas, afirmando que o valor de mercado agregado ao material biológico decorre da aplicação de um conjunto de meios de produção (capital-trabalho) e não apenas de alguns deles (dados e informaçöes genéticas).

A asscciação do conhecimento científico aos demais meios de produção é que permite, seguindo esse raciocínic, à fabiicáção de produtos destinados à venda no mercado, e, por isso, o Direito tem se pronunciado para afirmar que o trabalho científico constitui apenas um desses meios organizados e disponibilizados pelo empreendedor, que, via de conseqüência, deve ser reconhecido como titular do produto. ${ }^{11}$

Nesse particular, o Direito tem se utilizado, de forma peculiar, de instrumentos do direito autoral, para afirmar que a sim- ples urganização de dados biológicos (genéticos), a verificação de suas propriedades naturais e a identificação dessas propriedades com o conjunto de informações genéticas humanas não constituem invenção, no sentido jurídico, que habilite o pesquisador a se transformar em titular de direitos sobre o resultado da pesquisa, com efeitos patrimoniais e extrapatrimoniais.

Para esclarecer essa limitação ao reconhecimento da titularidade do cientista sobre o resultado do mapeamento genético humano, aprimorou-se a distinção entre invenção e descobrimento, o que significa dizer que o cientista não cria um novo organismo, não fabrica uma nova coisa, apenas aplica o conhecimento a algo já existente para permitir sua melhor compreensão (leitura). Desse modo, os resultados não são patenteáveis e não podem ser objeto de direitos de autoria intelectual. As informações genéticas estariam, portanto, disponíveis como os demais meios de produçãc, para serem utilizados como coisas pelo empreendedor. Diversa é a solução re. lativa a produtos elaborados com base nas informaçōes do genoma humano, os quais são patenteáveis, isto é, passíveis de serem juridicamente apropriados por sujeitos privados.

Colocada nesses termos a questão, é possível concluir que a Declaração sobre Genoma Humano e Direitos do Homem, em seu art. $4^{\circ}$, se restringe a proclamar a gratuidade do genoma em seu estado natu.

11. EDELMAN, Bernard. La personne en danger. Paris: PUF, 1999. p. 285-287. 
ral, mas não alcança o problema da onerosidade de produtos biotecnológicos.

Admitida a possibilidade de patenteamento de produtos genéticos, seu acesso, inclusive com fins terapêuticos, segue as regras de Direito Privado, vale dizer, depende de aquisição derivada onerosa, diversa da que ocorre com o acesso ao corpo humano, para fins de pesquisa, que é sempre gratuita.

A onerosidade dos produtos biotecnológicos, especialmente aqueles com finalidade terapêutica, tem sido apontada como uma nova forma de exclusão e de discriminação social. Sua gratuidade vem sendo reivindicada como uma exigência de políticas públicas coerentes com a cooperação gratuita que é emprestada por todos os disponentes em favor da Ciência e com a pauta de valores e princípios vigentes no Estado Democrático de Direito estabelecido, no Brasil, pela Constituição Federal de 1988.

A regulação ao acesso de produtos biotecnológicos, para uso terapêutico, sofre, por isso, o influxo de categorias próprias do Direito Público, com referência ao quadro constitucional.

Outro tipo de conflito que vem sedelineando é aquele que pode se estabelecer entre adquirentes e usuários de técnicas e produtos genéticos e terceiros, que sofram interferências em sua esfera jurídica, em virtude da aplicação desse uso. São bastan. te conhecidos e trabalhados pelo Direito o uso da informação, das terapias e da engenharia genética, no âmbito das relações familiares. Mas os reflexos dessa interferência também podem resultar na discriminação de sujeitos, especialmente no âmbito das relaçōes privadas de consumo e de trabalho, situações que o Direito vem, paulatinamente, tratando, para diminuir a presença de um sem fim de novas discriminações genéticas. ${ }^{12}$

Esse inventário de problemas, soluções e respectivas fundamentaçōes jurídicas, que provocam mudanças lentas no campo do Direito Público e Privado indicam, por outro lado, a emergência de instrumentos jurídicos calcados na lógica de comunidade.

A superação da dicotomia entre interesses públicos e privados, anunciam no texto da Declaração uma severa revisão principiológica do Direito, com vistas à readequação dos instrumentos jurídicos à realidade presente. ${ }^{13}$

Nessa linha de reconstrução teórica do instrumental jurídico, novas categorias se destinam, sobretudo, a redefinir a titularidade do sujeito sobre as coisas, ultrapassando a ética da autonomia individual e a racionalidade da propriedade privada, renovando a noção de dignidade humana $\mathrm{e}$ revitalizando as formas da contratualidade moderna.

\footnotetext{
12. No Brasil, o Projeto de Lein ${ }^{2} 149 / 97$ do Senado Federal, tramitando na Cámara dos Deputados sob ñ $4.610 / 98$, define os crimes resultantes da discriminaçăo genética.
}

13. KNOPPERS, Bartha Maria. Le génome humain: patrinoine commun de l'Humanité? Québec: Fides, 1999. p. 29-31. 
Em seu art. 2ª a Declaração contempla elementos de renovação do "pilar regulatório", utilizando-se de uma pauta de valores e princípios já aceita em outras Declaraçōes "Universais" e em ordenamentos jurídicos nacionais, especialmente, a dignidade da pessoa, o respeito às diferenças individuais e grupais e a preservação da biodiversidade, que admitem leituras particularizadas, com base em ideais universais, e o tornam mais permeável ao direito assentado no "pilar emancipatório".

O homem, como fonte elementar do genoma, é requalificado na comunidade humana e, em razão disso, passa a ter ampliada sua proteção pelos direitos humanos. A dimensão biológica do sujeito é ressaltada, mas deve ser compreendida no contexto social, de modo a evitar a redução do humano às suas características biológicas. Nesse sentido, os arts. $6^{2}$ e $7^{\circ}$ tratam, respectivamente, da vedação à discriminação fundada em características genéticas e da manutenção em sigilo dos dados genéticos. Essa nova dogmática principiológica reconhece, portanto, a vulnerabilidade humaina na socieúaủe ùe nueıcado e reafilund a noção iluminista de que todo o homem é fonte e fim do direito.

O conteúdo dessas novas fórmulas jurídicas está, desse modo, a depender de opções éticas e políticas que a Sociedade Ocidental venha tomar diante dos avanços da ciência e do apelo do mercado.

Para compreender esse conjunto de mudanças caberá, em primeiro plano, analisar os grandes grupos de posições políticas e teóricas que determinaram a formulação de instrumentos jurídicos internacionais sobre o genoma humano. Para tanto, há que se examinar, também, a inserção de tais posiçöes em um contexto político demar- cado por grupos de países exportadores e importadores de biotecnologia. Há que se considerar, ainda, a posição de países que são, primordialmente, fornecedores de material genético básico para a pesquisa, como o Brasil e de países como o Canadá, que desfrutam de posições especiais no contexto científico-econômico mundializado.

A interpretação judicial de conflitos de interesses dessa natureza, em países que oclipam a posição de exportadores de biotecnologia, permite, por outro lado, extrair critérios de decisão que tendam a se padronizar e se expandir como modelos jurídicos. Uma vez identificados esses critérios, cabe confrontá-los com as posições adotadas pela Declaração as quais pretendem atingir a comunidade internacional.

Nesse panorama, a definição do genoma humano como herança simbólica ou patrimônio comum da humanidade abre uma brecha $\epsilon$ impulsiona a revisão crítica de categorias do direito sobre as coisas (públicas ou privadas, materiais ou imateriais).

Por outro lado, o acompanhamento da gênese, desenvolvimento e efetiva aplicação da Declaração tornará visível se esse documento se inscreve como um novo modelo de regulação jurídica sobre a natureza, ou se apenas acrescenta elementos de complexidade na racionalidade moderna, a qual admite o poder jurídico do homem sobre todas as coisas.

De qualquer sorte, a leitura do texto da Declaração Universal sobre Genoma e Direitos Humanos permite, desde logo, vislumbrar pontos de ruptura com a racionalidade e as categorias jurídicas predominantes na modernidade, sinais de renovação do Direito clássico e, por vezes, a pura e simples manutenção dessa racionalidade dessas categorias. 